\title{
Quantitative evaluation of E. coli F4 and Salmonella Typhimurium binding capacity of yeast derivatives
}

\author{
Anja Ganner , Christian Stoiber, Jakob Tizian Uhlik, Ilse Dohnal and Gerd Schatzmayr
}

\begin{abstract}
The target of the present study was to quantify the capacity of different commercially available yeast derivatives to bind E. coli F4 and Salmonella Typhimurium. In addition, a correlation analysis was performed for the obtained binding numbers and the mannan-, glucan- and protein contents of the products, respectively. In a subsequent experiment, different yeast strains were fermented and treated by autolysis or French press to obtain a concentrated yeast cell wall. The capacity of yeast cell wall products to bind E. coli F4 and Salmonella Typhimurium was assessed with a quantitative microbiological microplate-based assay by measuring the optical density (OD) as the growth parameter of adhering bacteria. Total mannan and glucan were determined by HPLC using an isocratic method and a Refractive Index (RI) Detector. Total protein was determined by Total Kjeldahl Nitrogen (TKN). Statistical analyses were performed with IBM SPSS V19 using Spearman correlation and Mann Whitney U Test. Different yeast derivatives show different binding numbers, which indicate differences in product quality. Interestingly, the binding numbers for Salmonella Typhimurium are consistently higher (between one and two orders of magnitude) than for E. coli F4.

We could demonstrate some statistical significant correlations between the mannan- and glucan content of different yeast derivatives and pathogen binding numbers; however, for the different yeast strains fermented under standardized laboratory conditions, no statistically significant correlations between the mannan- and glucan content and the binding numbers for E. coli and Salmonella Typhimurium were found.

Interestingly, we could demonstrate that the yeast autolysis had a statistically significant difference on $E$. coli binding in contrast to the French press treatment. Salmonella binding was independent of these two treatments. As such, we could not give a clear statement about the binding factors involved. We propose that many more factors apart from mannan- and glucan content, such as cell wall structure, strain diversity, structural diversity, structural surroundings, and non-specific interactions play important roles in pathogen immobilization.
\end{abstract}

Keywords: Yeast cell wall, E. coli F4, Salmonella Typhimurium, Microplate-based assay

\section{Introduction}

Yeast derivatives such as yeast cell wall products and recently also yeast autolysate products are sold worldwide as feed supplements, some of which claim to bind enteropathogenic bacteria such as E. coli and Salmonella spp.. Although yeast cell wall products have been in the market for a long time, their binding capacity and the mechanism of pathogen binding is still not well understood. There is much confusion throughout the animal feed industry concerning the quality of yeast products.

* Correspondence: anja.ganner@biomin.net

BIOMIN Research Center, Technopark 1, 3430, Tulln, Austria
An important initial event in bacterial pathogenesis is the adherence of bacteria via their surface lectins to host intestinal cells. Infections are initiated only after the microorganism has first adhered to the host cell surface. If this initial adherence can be inhibited, so can the subsequent infection. This approach forms the basis of antiadherence strategies with the most studied being receptor-analogs, which include oligosaccharides (ShoafSweeney and Hutkins 2008).

According to the literature, mannan-oligosaccharides (MOS) are the substances in the yeast cell wall responsible for the binding of pathogens via mannose specific 
type-I fimbriae (e.g. Snellings et al. 1997; Sharon and Ofek 2000). However, questions have been raised of late as to whether the mannan quantity in the yeast cell wall is responsible for immobilizing enteric pathogens. A point made so far was the lack of quantitative analytical methods to determine the total amount of bacteria bound by the yeast cell wall (Applegate et al. 2010). Some qualitative test procedures such as the agglutination method are available to investigate the binding capacity of yeast products (e.g. Mirelman et al. 1980; Eshdat et al. 1981; Oyofo et al. 1989; Spring et al. 2000; Peng et al. 2001). The agglutination method mixes bacteria with a cell wall suspension followed by visual evaluation of binding. Critical issue with this procedure is the poor solubility of the yeast cell wall in aqueous dilutions. Furthermore visual evaluation of binding is highly subjective because it is not possible to determine whether the bacteria are actually bound or whether they are merely in proximity to the yeast. Thus reproducibility is not given. It is necessary to obtain the quantitative measurement of bacterial adhesion in order to evaluate the binding capacity and quality of yeast derivatives. The quantitative in vitro assay developed by Ganner et al. (2010) was used in the present study to investigate different yeast cell wall products (MOS) and yeast autolysates for their capacity to bind E. coli F4 and Salmonella Typhimurium. This method is based on a microtiter plate, the insolubility of the cell wall material, with its high molecular weight, can be used to coat the wells. The wells are allowed to be incubated with the test bacteria, unbound bacteria are rinsed out, and the growth rate of bound bacteria is subsequently quantified by optical density reading. The accuracy and reproducibility of binding is given by automated evaluation of optical density. However, in vitro assays may be criticized by product end users as not accurately reflecting in vivo responses. This may be true in some cases, but in others it may partially be a reflection of assay bias attributable to media selection, duration, or substrate concentration. Another limitation of this assay is that the binding mechanisms involved cannot be elucidated, for this purpose, studies on a molecular level and detailed characterization of cell wall components have to be examined in future research studies.

E. coli F4 and Salmonella Typhimurium were chosen for the present study as they are important pathogens in the animal sciences and are known to cause severe economic losses in livestock production. Furthermore, the mannan-, glucan- and protein content of the yeast products were determined and statistical evaluation for correlation was performed with IBM SPSS v19.

To collect more information on binding characteristics, a separate experiment was performed in addition to evaluating mannan- and glucan- content; eight different yeast strains were fermented in the laboratory, and subjected to autolysis and French press treatment, to investigate the potential influence of yeast strains and production methods.

\section{Material and methods Yeast derivatives}

Different types of commercially available yeast cell wall and autolysed yeast products were used. Due to a confidentiality agreement, the trade names and manufacturers have been omitted.

\section{Autolysis and French press of cell wall fragments}

Cell wall fragments were produced in the laboratory scale under standard conditions from the following yeast strains: Saccharomyces cerevisiae Bio 19 (DSMZ 1848), Klyveromyces marxianus Bio 21 (DSMZ 5420), Saccharomyces boulardii CAN 214, Saccharomyces boulardii HA 282, Saccharomyces boulardii HA 283, Trichosporon mycotoxinivorans Bio 328 (DSMZ 14153), Aureobasidium pullulans CF 10 (DSMZ 14940), Aureobasidium pullulans CF 40 (DSMZ 14941). Bio, CAN and HA belong to the BIOMIN Research Center culture collection.

Cell wall fragments were obtained by incubating the respective yeast strains in $1000 \mathrm{ml}$ shaking flasks containing a $400 \mathrm{ml}$ medium consisting of $1 \%$ soy peptone, $0.1 \%$ yeast extract, $0.2 \%$ magnesium sulfate heptahydrate, $0.2 \%$ ammonium sulfate, $1 \%$ saccharose and $2.5 \%$ glucose for 48 hours at $30^{\circ} \mathrm{C}$ and $\mathrm{pH} 5.0$. The yeast cells were subsequently autolysed by incubating at $\mathrm{pH} 5$ at a temperature of $50^{\circ} \mathrm{C}$ for 24 hours and centrifuged $(17700 \times \mathrm{g}, 10 \mathrm{~min})$ to separate cell wall fragments from the supernatant. Finally, the cell wall fragments were freeze dried $\left(24\right.$ hours, $-30^{\circ} \mathrm{C} /+30^{\circ} \mathrm{C}, 0.001$ mbar) (Epsilon 2-90, Christ, Osterode, Germany). Autolysis was adapted according to Liu et al. (2008). The degree of autolysis was assessed by analysis of the supernatant fraction: cell rupture leads to increasing amounts of proteins and carbohydrates and dry matter in the supernatant. These parameters reached a maximum value after 24 hours. The progress of autolysis was also monitored by observing cells under the microscope (magnified 1000 times) and comparing them to cells from the original culture.

French press: Rupture took place in the French press with 1 cycle at 20,000 psi (=1,378.96 bar). Microscopic images are taken of the ruptured cells. Liquid supernatant was removed from the non-soluble cell walls by centrifugation $(17700 \times \mathrm{g}, 10 \mathrm{~min})$.

\section{Microplate-binding assay \\ Principle}

The quantitative adhesion of E. coli F4 (Bio 104 from BIOMIN Research Center culture collection) and Salmonella Typhimurium (Bio 99 from BIOMIN Research Center culture collection) on yeast products was deter- 
mined by measuring the optical density of the culture solutions, which indicates the growth of the adhering bacteria. The growth rate depended on the number of adhering bacteria - with higher numbers bound resulting in faster growth and thus the bacteria entering earlier into the exponential phase.

\section{Assay}

The yeast derivatives were suspended in phosphate buffered saline (PBS) in a concentration of $0.1 \mathrm{mg} / \mathrm{L}$, the wells of a 96-well plate were coated with a $100 \mu \mathrm{L}$ yeast suspension per well and incubated for $16-18$ hours at $4{ }^{\circ} \mathrm{C}$. The plate was washed three times with PBS Tween 20 using a microplate washer (Tecan 5082 M8/4R Columbus Plus). Subsequently, the bacterial suspension of $E$. coli F4 or Salmonella Typhimurium grown in Tryptic Soy Broth (TSB) overnight was adjusted to OD 0.01 and added to the wells of the microplate. Bacteria were allowed to adhere for 60 minutes at $37^{\circ} \mathrm{C}$ and the plate was subsequently washed 6 times with a microplate washer/PBS Tween 20 to remove non-adherent bacteria. The wells were filled with $200 \mu \mathrm{L}$ of TSB and overlaid with one drop of paraffin- oil. Blank, growth controls, negative control and binding control were also assessed.

The microplate was placed in a microplate reader (Tecan Genious), incubated for 18 hours at $37^{\circ} \mathrm{C}$ and OD was measured at a wavelength of $690 \mathrm{~nm}$. Data were recorded every 15 minutes.

Serial dilutions of E. coli or Salmonella were prepared and applied in parallel on the microplate and the agar plate in order to establish a linear regression between the number of counted bacteria on the agar plate (CFU/ $\mathrm{mL}$ ) and the time in hours when the adhering bacterial solution reached the exponential phase (optical density of 0.1 at $690 \mathrm{~nm}$ ). Independent calibration curves were created for the genera E. coli and Salmonella. Subsequently, the number of bacteria bound to the yeast product was determined using linear regression.

The binding control consisted of Bovine Serum Albumin (BSA) and test bacteria but without adding yeast to determine the non-specific binding sites. The binding control had no growth until after 6 hours. Finally the binding control, the bacterial number, which adhered to the non-specific binding sites of the well, was subtracted from the calculated data to determine the final number of specifically adhering bacteria. The blank consisted of the yeast cell wall product and BSA but without adding test bacteria and included all the assay steps to determine the bacterial number of the yeast cell wall product. The blank had no growth until after $10 \mathrm{~h}$. The media control (TSB) had no growth until after $18 \mathrm{~h}$.

The calibration is valid only for the respective genera and at an optical density of 0.1 (Ganner et al. 2010).

\section{Carbohydrate and protein analysis}

For total mannan and glucan determination, yeast cell wall polysaccharides were hydrolyzed with $72 \%$ sulfuric acid. Carrez-precipitation was subsequently performed to remove interfering proteins and fats by precipitation as zinc (2+) and/or cyanoferrat (II) - complexes (Matissek et al. 1992). The cleared supernatants were analyzed for glucose and mannose by HPLC-RID using an ICSep ION300 column (Transgenomic).

Total protein was determined by Total Kjeldahl Nitrogen (TKN, AOAC Official Method 954.01, 1954).

Carbohydrate analyses were conducted in single, protein analyses were conducted in duplicates.

\section{Statistical analysis}

Experimental data were analyzed using IBM SPSS, version 19. Due to non-normal distribution of data, Spearman correlation was used. The calculated coefficient of correlation is only relevant for a given significance value (P-value $<0.05$ ); the coefficients are classified as below. A positive Spearman correlation coefficient corresponds to an increasing monotonic trend between $X$ and $Y$. A negative Spearman correlation coefficient corresponds to a decreasing monotonic trend between $X$ and $Y$. The influence of treatment (autolysis or French press) was calculated with the non-parametric Mann Whitney $U$ Test (data non-normal distributed).

\section{Coefficient of correlation classification}

Correlations were considered very low $(r \leq 0.2)$, low $(0.2<\mathrm{r} \leq 0.5)$, medium $(0.5<\mathrm{r} \leq 0.7)$, high $(0.7<\mathrm{r} \leq 0.9)$, very high $(0.9<\mathrm{r} \leq 1)$.

\section{Results}

Different commercially available yeast cell wall products and autolysate products were tested for their ability to bind E. coli F4 and Salmonella Typhimurium: E. coli F 4 binding numbers ranged between $10^{1}$ and $10^{3} \mathrm{CFU} / \mathrm{mg}$ yeast; Salmonella Typhimurium binding numbers between $10^{3}$ and $10^{4} \mathrm{CFU} / \mathrm{mg}$ yeast. The analysis of the mannan-, glucan-, and protein content of the yeast products were also presented: Mannan contents ranged between 3\% and $28 \%$; glucan contents between $12 \%$ and $68 \%$, and protein contents between $3 \%$ and $45 \%$ (Table 1 ).

The results of the Spearman correlation analysis revealed a statistically significant correlation between mannan content and E. coli $\mathrm{F} 4$ binding $(\mathrm{P}=0.005)$ and between glucan content and Salmonella Typhimurium binding $(\mathrm{P}<0.001)$. The coefficient of correlation was 0.315 (low correlation) for E. coli and mannan and 0.754 (high correlation) for Salmonella Typhimurium and glucan. No statistically significant correlation was found between glucan content and $E$. coli binding $(\mathrm{P}=0.257)$ or between protein content and $E$. coli binding $(\mathrm{P}=0.06)$. There was also no statistically 
Table 1 Analysis of different yeast derivatives (3 replicates): amount of bound E. coli F4 and Salmonella Typhimurium (CFU/mg yeast); mannan-, glucan-, and protein-content (in \% of dry matter)

\begin{tabular}{llllll}
\hline Yeast derivative & E. coli F4 (CFU/mg yeast) & Salmonella Typhimurium (CFU/mg yeast) & Glucan (\% DM) & Mannan (\% DM) & Protein (\% DM) \\
\hline cell wall 1 & $50,50,100$ & $26000,41000,49200$ & 37.75 & 19.71 & 26.40 \\
cell wall 2 & $125,115,85$ & $12200,36900,37900$ & 28.81 & 11.97 & 30.7 \\
cell wall 3 & 2300, 2100, 1900 & $80000,153000,125000$ & 27.94 & 28.78 & 26.40 \\
cell wall 4 & - & $1100,300,600$ & 20.48 & 11.95 & 36.00 \\
cell wall 5 & 35,40 & $1300,27000,40000$ & 26.94 & 6.92 & 30.90 \\
autolysate 1 & $130,100,110$ & $6000,6500,5400$ & 12.60 & 5.14 & 45.80 \\
autolysate 2 & $80,230,216$ & $30000,65000,78000$ & 23.62 & 14.75 & 40.10 \\
autolysate 3 & $67,95,130$ & $49000,59000,60000$ & 22.84 & 16.39 & 38.20 \\
autolysate 4 & $1200,900,1000$ & $78000,130000,37000$ & 23.08 & 17.68 & 38.10 \\
autolysate 5 & $150,350,100$ & $48000,59000,78000$ & 22.66 & 16.15 & 36.40 \\
Yeast derivative 1 & $216,130,100$ & $8900,6000,9000$ & 68.38 & 11.37 & 3.90 \\
Yeast derivative 2 & $5,10,25$ & $4000,1000,4000$ & 59.04 & 3.25 & 5.30 \\
\hline
\end{tabular}

significant correlation between mannan content and Salmonella binding $(\mathrm{P}=0.07)$ or protein content and Salmonella binding $(\mathrm{P}=0.21)$ (Table 2, Table 3$)$.

Furthermore, we analyzed different yeast strains for their capability to bind E. coli F4 and Salmonella Typhimurium. E. coli binding ranged between $10^{1}$ and $10^{3} \mathrm{CFU} / \mathrm{mg}$ and Salmonella binding between $10^{4}$ and $10^{5} \mathrm{CFU} / \mathrm{mg}$. Glucan contents ranged between $16 \%$ and 39\%, mannan content between $3 \%$ and $23 \%$, and protein contents between $14 \%$ and 39\% (Table 4). No statistically significant correlation (Spearman correlation analysis) between the mannan-, glucan-, or the protein content and the binding numbers for E. coli and Salmonella Typhimurium were noted.

The Mann Whitney $U$ Test demonstrated an influence of the yeast autolysis on E. coli binding in contrast to French press treatment $(\mathrm{P}<0.001)$. For Salmonella binding, no influence was noted due to autolysis or French press treatment $(\mathrm{P}=0.27)$.

\section{Discussion}

Yeast cell wall fractions and yeast autolysate products have been proposed to bind enteropathogenic bacteria and therefore to possess prophylactic properties in the gut for the control of selective pathogenic bacteria such as E. coli and Salmonella. There is much in the literature describing this adherence mechanism and mode(s) of action of yeast derivatives (Mourao et al. 2006; Oyofo et al. 1989; Sharon and Ofek 2000; Shoaf-Sweeney and Hutkins 2008; Snellings et al. 1997; Spring et al. 2000; Terre et al.
2007; Yang et al. 2008). However, no study has ever investigated the quantitative number of pathogens bound by different yeast derivatives. The influences of yeast strains and production treatments (autolysis or French press) have also not been investigated before in combination with pathogen binding. We consider this an important quality parameter for yeast cell wall products. Indeed, there was a lack of quantitative analytical methods to determine the total amount of bacteria bound by the yeast cell wall (Applegate et al. 2010). Yeast cell wall products are believed to act as anti-adhesive agents and are thus able to prevent intestinal bacterial attachment by providing alternative adhesion sites to enterobacteria which contain mannose-specific type I fimbriae such as E. coli and Salmonella spp. (Ofek et al. 1977). Shoaf-Sweeney and Hutkins (2008) defined the adhesion affinity by the valency of protein-oligosaccharide interactions. A single molecule would have a low affinity but the creation of individual protein subunits with numerous oligosaccharide binding sites assembled to a filamentous structure leads to increased target avidity. The present study demonstrates that mannan content is an important parameter for E. coli binding $(r=0.315$, low Spearman correlation), and glucan content has a high correlation with Salmonella Typhimurium binding affinity $(r=0.754)$. According to the current results and further evaluating the available literature, we propose that there are many more unknown factors (apart from mannan and glucan content) influencing binding affinity of these pathogens.

Table 2 Spearman correlation between quantity of bound E. coli F4 (CFU/mg yeast) and mannan-, glucan-, and protein-content of yeast derivatives

\begin{tabular}{|c|c|c|c|c|c|}
\hline & & & Glucan [\%] & Mannan [\%] & Protein [\%] \\
\hline \multirow[t]{2}{*}{ Spearman-Rho } & CFU E. coli [CFU/mg yeast] & Coefficient of correlation & -0.130 & 0.315 & 0.214 \\
\hline & & Sig. (2-side) & 0.257 & 0.005 & 0.060 \\
\hline
\end{tabular}


Table 3 Spearman correlation between quantity of bound Salmonella Typhimurium (CFU/mg yeast) and mannan-, glucan-, and protein-content of yeast derivatives

\begin{tabular}{lllrr}
\hline & & Glucan [\%] & Mannan [\%] & Protein [\%] \\
\hline Spearman-Rho & CFU Salmonella [CFU/mg yeast] & Coefficient of correlation & 0.754 & 0.202 \\
& & Sig. (2-side) & 0.000 & 0.143 \\
& & & 0.077 & 0.210 \\
\hline
\end{tabular}

In addition to the total amount of mannan and glucan, the three-dimensional structure of mannose chains within the yeast cell wall is another critical factor to consider. We observed that mannose chains have a strong influence on the binding behavior of different yeast cell wall products and are important for pathogen immobilization. This is supported by the observation that in contrast to yeast cell wall products (mannan content between 10-25\%), a purified mannan standard (99\%) showed no pathogen binding activity (Ganner et al. 2007, unpublished data). Indeed, quantitative, rather than qualitative assays are essential in order to evaluate the pathogen binding capacity of cell walls from different yeast sources and strains (Ganner et al. 2008). Ofek et al. (2003)

Table 4 Analysis of different yeast strains (standardized laboratory fermentation and autolysis or French press treatment) on E. coli F4 and Salmonella Typhimurium binding capability (3 replicates); mannan-, glucan-, and protein-content

\begin{tabular}{|c|c|c|c|c|c|}
\hline Yeast & $\begin{array}{l}\text { E. coli F4 } \\
\text { (CFU/mg yeast) }\end{array}$ & $\begin{array}{l}\text { Salmonella Typhimurium } \\
\text { (CFU/mg yeast) }\end{array}$ & Glucan (\% DM) & Mannan (\% DM) & Protein (\% DM) \\
\hline Saccharomyces cerevisiae HA 282* & $100,900,300$ & $200000,50000,55000$ & 19.09 & 23.67 & 39.41 \\
\hline \multicolumn{6}{|l|}{ Autolysis } \\
\hline Saccharomyces cerevisiae HA 282* & $1000,400,4000$ & $600000,170000,80000$ & 19.03 & 23.07 & 38.65 \\
\hline \multicolumn{6}{|l|}{ French press } \\
\hline Saccharomyces cerevisiae HA 283* & $3500,2000,1800$ & $90000,80000,110000$ & 16.81 & 23.84 & 35.08 \\
\hline \multicolumn{6}{|l|}{ Autolysis } \\
\hline Saccharomyces cerevisiae HA 283* & $100,60,10$ & $260000,100000,120000$ & 16.45 & 21.69 & 34.68 \\
\hline \multicolumn{6}{|l|}{ French press } \\
\hline Saccharomyces cerevisiae CAN 214* & $2000,3000,600$ & $230000,155000,100000$ & 15.09 & 20.41 & 36.12 \\
\hline \multicolumn{6}{|l|}{ Autolysis } \\
\hline Saccharomyces cerevisiae CAN 214* & $1700,700,270$ & $350000,90000,45000$ & 16.62 & 22.41 & 33.03 \\
\hline \multicolumn{6}{|l|}{ French press } \\
\hline Saccharomyces cerevisiae Bio 19* (DSMZ 1848) & $3000,4000,3500$ & $160000,100000,165000$ & 16.99 & 22.7 & 34.43 \\
\hline \multicolumn{6}{|l|}{ Autolysis } \\
\hline Saccharomyces cerevisiae Bio 19* (DSMZ 1848) & $100,1500,350$ & $66000,56000,27000$ & 16.41 & 20.92 & 33.94 \\
\hline \multicolumn{6}{|l|}{ French press } \\
\hline Klyveromyces marxianus Bio 21* (DSMZ 5420) & $2400,1700,2200$ & $400000,290000,240000$ & 28.34 & 4.1 & 43.63 \\
\hline \multicolumn{6}{|l|}{ Autolysis } \\
\hline Klyveromyces marxianus Bio 21* (DSMZ 5420) & $450,4500,450$ & $150000,100000,86000$ & 25.49 & 3.12 & 47.13 \\
\hline \multicolumn{6}{|l|}{ French press } \\
\hline $\begin{array}{l}\text { Trichosporon mycotoxinivorans Bio } 328^{*} \\
\text { (DSMZ 14153) }\end{array}$ & $7000,1700,1500$ & $35000,30000,25000$ & 23.21 & 9.46 & 16.86 \\
\hline \multicolumn{6}{|l|}{ Autolysis } \\
\hline $\begin{array}{l}\text { Trichosporon mycotoxinivorans Bio 328* } \\
\text { (DSMZ 14153) }\end{array}$ & $400,500,2000$ & $110000,90000,66000$ & 24.69 & 9.66 & 14.53 \\
\hline \multicolumn{6}{|l|}{ French press } \\
\hline Aureobasidium pullulans CF10* (DSMZ 14940) & $3000,3500,1700$ & $130000,100000,15000$ & 39.37 & 4.95 & 35.51 \\
\hline \multicolumn{6}{|l|}{ French press } \\
\hline Aureobasidium pullulans CF 40* (DSMZ 14941) & $400,2500,1000$ & $40000,27000,15000$ & 31.90 & 5.33 & 32.94 \\
\hline French press & & & & & \\
\hline
\end{tabular}

*BIOMIN Research Center collection number. 
explained that apart from adhesion-receptor interaction, hydrophobic and other non-specific interactions might be involved in the adhesion process.

Becker and Galetti (2008) investigated various food and feed components for alternative adhesion of intestinal E. coli and Salmonella. Yeast mannan-oligosaccharides, pumpkin, sesame seed extract, palm kernel extract and konjac gum were among the strongest binding matrices for enteropathogens. Adhesion matrices differ tremendously which gives rise to various interpretations and speculations on substantial binding factors while suggesting that unspecific and unknown binding properties are involved. Moreover, taking into account the diversity of natural products and biological variation therein, the binding capacity of fibrous food and feed components for different bacteria seems rather unpredictable (Becker and Galetti, 2008).

Our observation that mannan content is strain dependent (Table 4) agrees with other studies (Jaehrig et al. 2008; Klis et al. 2002; Molnar et al. 2004). However, in our experiment with different yeast strains fermented under standardized laboratory conditions, we could not obtain any statistically significant correlations between mannan or glucan content and pathogen binding. According to these results, the yeast strain itself has no influence on E. coli F4 or Salmonella Typhimurium binding. However, we could demonstrate that the downstream process autolysis has an influence on $E$. coli binding $(\mathrm{P}<0.001)$. Giovani et al. (2010) studied the effect of yeast strain and fermentation conditions on the release of cell wall polysaccharides. Temperature, media and sugar composition influenced the release of cell wall polysaccharides significantly. These data underline and support our results on the relative influence of production processes and production conditions on binding capacity.

The binding mechanism between pathogens and the yeast cell wall can be speculated, as demonstrated by the autolysis production process, the mannan content and the glucan content. However, as these binding mechanisms are only partially understood, we propose that other factors such as the cell wall structure, strain diversity, structural surroundings-, and non-specific interactions might also play important roles in pathogen immobilization, in addition to the total amount of mannan or glucan.

Summarizing, the present study demonstrates a variation among different yeast products concerning their capability to bind E. coli F4 and Salmonella Typhimurium. Salmonella Typhimurium was bound one to two orders of magnitude more than E. coli $\mathrm{F} 4$. We could demonstrate a statistically significant correlation between mannan and glucan content and pathogen binding. Furthermore we could demonstrate a relative influence of the production process autolysis.
However, the binding mechanisms involved are still not fully understood and our results underline the complexity of the present subject. The recently suggested mannose specific type-I fimbriae play a role and furthermore, unknown mechanisms which might interact synergistically are probably involved. Biological variation and natural diversity make predictions even more difficult and comprehensive. Further research is necessary, e. g., on a molecular level and a detailed characterization of cell wall components and cell wall structure, to elucidate on the additional forces which might be involved in the binding mechanism between yeast derivatives and enteropathogenic bacteria. Finally, additional standardized in vivo experiments with challenged animals could also further validate the binding potential of yeast products and the study of the anti-adherence strategy.

\section{Competing interests}

The authors declare that they have no competing interests.

\section{Acknowledgements}

I would like to thank Barbara Doupovec for the statistical analysis.

Received: 29 August 2013 Accepted: 9 October 2013

Published: 22 October 2013

\section{References}

Applegate TJ, Klose V, Steiner T, Ganner A, Schatzmayr G (2010) Probiotics and phytogenics for poultry: Myth or reality? J Appl Poultry Res 19:194-210

Becker PM, Galetti S (2008) Food and feed components for gut health-promoting adhesion of E. coli and Salmonella enteric. J Sci Food Agric 88:2026-2035

Eshdat Y, Speth V, Jann K (1981) Participation of pili and cell wall adhesion in the yeast agglutination activity of Escherichia coli. Infect Immun 34:980-986

Ganner A, Fink L, Schatzmayr G (2008) Quantitative in vitro assay to evaluate yeast products concerning their binding activity of enteropathogenic bacteria. J Anim Sci 86(E.Suppl. 2):54

Ganner A, Stoiber C, Wieder D, Schatzmayr G (2010) Quantitative in vitro assay to evaluate the capability of yeast cell wall fractions from Trichosporon mycotoxinivorans to selectively bind gram negative pathogens. J Microbiol Methods 83:168-174

Giovani G, Canuti V, Rosi I (2010) Effect of yeast strain and fermentation condition on the release of cell wall polysaccharides. Int J Food Microbiol 137(2-3):303-307

Jaehrig SC, Rohn S, Kroh LW, Wildenauer FX, Lisdat F, Fleischer LG, Kurz T (2008) Antioxidative activity of (1-3), (1-6)-beta-D-glucan from Saccharomyces cerevisiae grown on different media. LWT Food Sci Technol 41:868-877

Klis FM, Boorsma A, De Grot PWJ (2002) Cell wall construction in Saccharomyces cerevisiae. Yeast 23:185-202

Liu XY, Wang Q, Cui SW, Liu HZ (2008) A new isolation method of beta-D-glucans from spent yeast Saccharomyces cerevisiae. Food Hydrocoll 22:239-247

Matissek R, Schnepel F, Steiner G (1992) Lebensmittelanalytik, 2. Auflage, Springer Verlag Berlin Heidelberg New York, Berlin and Heidelberg (Springer Verlag)

Mirelman D, Altmann G, Eshdat Y (1980) Screening of bacterial isolates for mannosespecific lectin activity by agglutination of yeasts. J Clin Microbiol 11:328-331

Molnar O, Schatzmayr G, Fuchs E, Prillinger H (2004) Trichosporon mycotoxinivorans sp. nov., a new yeast species useful in biological detoxification of various mycotoxins. Syst Appl Microbiol 27:661-671

Mourao JL, Pinheiro V, Alves A, Guedes CM, Pinto L, Saavedra MJ, Spring P, Kocher A (2006) Effect of mannan oligosaccharides on the performance, intestinal morphology and cecal fermentation of fattening rabbits. Anim Feed Sci Technol 126:107-120

Ofek I, Mirelman D, Sharon N (1977) Adherence of Escherichia coli to human mucosal cells mediated by mannose receptors. Nature 265:623-625

Ofek I, Hasty DL, Sharon N (2003) Anti-adhesion therapy of bacterial diseases: Prospects and problems. FEMS Immunol Med Microbiol 38:181-191 
Oyofo BA, Droleskey RE, Norman JO, Mollenhauer HH, Ziprin RL, Corrier DE, DeLoach JR (1989) Inhibition by mannose of in vitro colonization of chicken small intestine by Salmonella typhimurium. Poult Sci 68:1351-1356

Peng X, Sun J, Michiels C, Iserentant D, Verachtert H (2001) Coflocculation of Escherichia coli and Schizosaccharomyces pombe. Appl Microbiol Biotechnol 57:175-181

Sharon N, Ofek I (2000) Safe as mother's milk: carbohydrates as future antiadhesion drugs for bacterial diseases. Glycoconj J 17:659-664

Shoaf-Sweeney KD, Hutkins RW (2008) Chapter 2 adherence, anti-adherence, and oligosaccharides. Prevent Patho Stick Host:101-161

Snellings NJ, Tall BD, Venkatesan MM (1997) Characterization of Shigella type 1 fimbriae: expression, FimA sequence, and phase variation. Infect Immun 65:2462-2467

Spring P, Wenk C, Dawson KA, Newman KE (2000) The effects of dietary mannan Oligosaccharides on cecal parameters and the concentrations of enteric bacteria in the ceca of Salmonella-challenged broiler chicks. Poult Sci 79:205-211

Terre M, Calvo MA, Adelantado C, Kocher A, Bach A (2007) Effects of mannan oligosaccharides on performance and microorganism fecal counts of calves following an enhanced-growth feeding program. Anim Feed Sci Technol 137:115-125

Yang Y, lji PA, Kocher A, Mikkelsen LL, Choct LL (2008) Effects of mannan oligosaccharide and Fructooligosaccharide on the response of broilers to pathogenic Escherichia coli challenge. Br Poult Sci 49:550-559

doi:10.1186/2191-0855-3-62

Cite this article as: Ganner et al:: Quantitative evaluation of E. coli F4 and Salmonella Typhimurium binding capacity of yeast derivatives. AMB Express 2013 3:62.

\section{Submit your manuscript to a SpringerOpen ${ }^{\circ}$ journal and benefit from:}

- Convenient online submission

- Rigorous peer review

- Immediate publication on acceptance

- Open access: articles freely available online

- High visibility within the field

- Retaining the copyright to your article

Submit your next manuscript at $\gg$ springeropen.com 